\title{
Correction to: Circular RNA profiling and its potential for esophageal squamous cell cancer diagnosis and prognosis
}

\author{
Liyuan Fan', Qiang Cao ${ }^{2}$, Jia Liư ${ }^{3}$, Junpeng Zhang ${ }^{1}$ and Baosheng $\mathrm{Li}^{1{ }^{*}}$
}

\section{Correction to: Mol Cancer \\ https://doi.org/10.1186/s12943-018-0936-4}

After publication of the article [1], an error was noticed in the Funding section. The funding number provided was 2016YFC0105100 and should be corrected to 2016YFC0105106. We apologize for this error, which does not affect any of the interpretations or conclusions of the article.

\section{Author details}

'Department of Radiation Oncology, Shandong Cancer Hospital Affiliated to Shandong University, Jinan 250117, China. ${ }^{2}$ School of Computer Science and Engineering, Southeast University, Nanjing, China. ${ }^{3}$ Department of Clinical

Laboratory, The Second Hospital of Shandong University, Jinan, China.

Published online: 05 August 2019

\section{Reference}

1. Fan L, Cao Q, Liu J, Zhang J, Li B. Circular RNA profiling and its potential for esophageal squamous cell cancer diagnosis and prognosis. Mol Cancer. 2019;18:16. https://doi.org/10.1186/s12943-018-0936-4.

\footnotetext{
*Correspondence: baoshli1963tg@163.com

'Department of Radiation Oncology, Shandong Cancer Hospital Affiliated to Shandong University, Jinan 250117, China

Full list of author information is available at the end of the article
} 